\title{
A jurisprudência do Tribunal Europeu dos Direitos do Homem sobre o fim da vida
}

ECHR's case law on the end of life

Jurisprudencia del Tribunal Europeo de Derechos Humanos sobre el final de la vida

Nuno Manuel Pinto Oliveira ${ }^{1}$

\section{Introdução}

\section{O conceito e os tipos de eutanásia}

O conceito de eutanásia é decididamente difícil de definir. Adragão (1) afirma, p. ex., que a "ambiguidade [...] quase obstinada" com que o termo eutanásia é correntemente empregue constitui "a dificuldade principal no debate actual"

A afirmação é, com toda a probabilidade, excessiva; em todo o caso, ainda que a afirmação seja com toda a probabilidade excessiva, deve concordar-se com um princípio de precedência dos problemas relativos a conceitos sobre os problemas relativos a regimes. Os conceitos fixam o quadro dentro do qual pode aplicar-se sos princípios e as regras relevantes para resolver os problemas relativos a regimes (2)

Evitando toda a ambiguidade, diremos que o conceito de eutanásia deve ser um conceito determinado pela função (3) designando os casos em que se põe um particular problema de regime - o problema da relativização do bem ou valor da vida por força da sua ponderação com os bens ou valores da autonomia e do bem-estar dos pacientes (4)

Eutanásia será uma acção ou uma omissão por que se causa a morte de uma pessoa a seu pedido ou, ainda que não seja a seu pedido, no seu interesse — para evitar o seu sofrimento ou, não tendo sido possível evitar o seu sofrimento, para o atenuar ${ }^{2}$ (5). "A vida da pessoa é tão má, ou tornar-se-á tão má, que a pessoa estará melhor morta" (6)

\footnotetext{
1 Professor catedrático da Escola de Direito da Universidade do Minho (Braga, Portugal). E-mail: npo@direito.uminho.pt

2- Define-se eutanásia como "conjunto de acções (eutanásia activa) ou omissões (eutanásia passiva), praticadas por outrem que não o afectado, em regra por profissional(is) de saúde (maxime, médicos), visando praticar a morte, a seu pedido ou não, sendo esta conduta determinada pelos simples respeito pela autonomia ou por, no caso, se verificarem determinadas indicações, tradicionalmente a dor ou o sofrimento, de moribundo ou doente incurável".
} 
Entre os corolários da definição enunciada encontram-se os três seguintes: Em primeiro lugar, ao definirmos a eutanásia como acção ou omissão, propomo-nos ampliar o conceito de eutanásia de forma a abranger a eutanásia activa, de quando em quando chamada de eutanásia positiva, e a eutanásia passiva, de quando em quando chamada de eutanásia negativa. Em segundo lugar, ao definirmos a eutanásia como acção ou omissão por que se causa a morte de uma pessoa, propomo-nos ampliar o conceito de forma a abranger a eutanásia activa directa e a eutanásia activa indirecta. Em terceiro lugar, ao definirmos a eutanásia como acção ou omissão por que se causa a morte de uma pessoa a seu pedido ou, ainda que não seja a seu pedido, no seu interesse, propomo-nos amplicar o conceito de forma a abranger a eutanásia voluntária e a eutanásia involuntária.

O termo eutanásia activa ou positiva designa os casos o sujeito age para provocar a morte e o termo eutanásia passiva ou negativa, os casos em que o sujeito não age para a prevenir. Em termos simples (algo simplista), eutanásia passiva significa deixar morrer.

O conceito de eutanásia activa compreende a eutanásia activa directa, em que a intenção do agente é "acelerar a morte", e a eutanásia activa indirecta, em que a intenção do agente é, tão-só, diminuir o sofrimento do doente, administrando-lhe analgésicos (7): "[A morte] [...] é aceite e tolerada como um efeito negativo proporcional ao efeito positivo que se procura, qual seja, a diminuição do sofrimento" (7) (8) (9).

Em alguns autores (10), o termo eutanásia activa indirecta é substituído por ortotanásia. Se a causação da morte de um doente fosse directa, deliberada (7) ou intencional, haveria eutanásia; se a causação da morte fosse indirecta, decorrendo do cumprimento do dever de agir para diminuir o sofrimento, não haveria eutanásia nenhuma - haveria ortotanásia. Barroso e Martel, p. ex., definem-na como "a morte em tempo adequado" (10) - nem antecipada, como acontece na eutanásia, nem tão-pouco retardada, como acontece na distanásia. O conceito de ortotanásia encontrar-se-ia intimamente ligado aos cuidados paliativos, por que se pretende evitar o sofrimento do paciente ou atenuar o sofrimento não evitado ou não evitável (10) Com o recurso ao termo ortotanásia pretender-se-ia significar que a morte ocorrida como uma consequência ou como um efeito colateral dos cuidados paliativos é ainda uma "morte em tempo adequado".

Concordando com Díez Ripolles, consideramos o problema só pode representar-se e resolver-se de uma forma adequada "recupera[ndo] a clareza e a neutralidade conceptuais" (11) Os termos eutanásia directa e eutanásia indirecta, como os termos 
eutanásia intencional e eutanásia não intencional, designam de facto diferentes contextos de ponderação. O problema da relativização do valor da vida, por força da sua ponderação, pode pôr-se, e põe-se, de forma diferente, consoante a eutanásia seja directa ou indirecta, intencional ou não intencional. $O$ facto de os dois conceitos designarem diferentes contextos de ponderação só confirma, porém, uma coisa - que o problema é, como em todos os casos de eutanásia, um problema de ponderação (2)

O conceito de eutanásia passiva compreende a omissão inicial e a omissão superveniente, por interrupção do tratamento (12): Na eutanásia passiva por omissão inicial do tratamento causa-se a morte de uma pessoa, por não se adoptarem as medidas que prolongariam a sua vida; deixa-se morrer a pessoa, através de uma abstenção terapêutica, ou seja: por não se iniciar nenhum tratamento. Na eutanásia passiva por omissão superveniente de tratamento causa-se a morte de uma pessoa, por se interromperem as medidas adoptadas; deixa-se morrer a pessoa, através de uma interrupção terapêutica, ou seja: por não se continuar o tratamento iniciado ${ }^{3}$ (13).

O termo eutanásia voluntária designa as hipóteses em que uma pessoa capaz de formar uma vontade livre e esclarecida e de agir conforme a sua vontade [livremente formada] faz um pedido para que a matem ou para que a deixem morrer. $O$ termo eutanásia involuntária, esse, pode designar uma de duas hipóteses: pode suceder, por um lado, que a pessoa não tenha formado uma vontade livre e esclarecida ou que, tendo-a formado, não a tenha declarado; pode suceder, por outro lado, que uma pessoa capaz de formar uma vontade livre e esclarecida e de agir conforme a sua vontade [livremente formada] faça o pedido de que não a matem (ou de que não a deixem morrer) (6)

Os autores anglo-saxónicos distinguem terminologicamente as duas situações dando-se o caso de a pessoa não ter feito nenhum pedido, haveria uma non voluntary euthanasia ; dando-se o caso de ter feito um pedido de que não a matassem, ou de que não a deixassem morrer, haveria uma involuntary euthanasia(14) Evitando a dificuldade de traduzir non voluntary euthanasia, falaremos de eutanásia sem um pedido do paciente e, evitando a dificuldade de traduzir involuntary euthanasia, falaremos de

\footnotetext{
${ }^{3}$ Chamando a atenção para o facto de que a intervenção só pode começar desde que o paciente dê o seu consentimento e só pode continuar desde que o paciente não deixe de o dar (= desde que o paciente não 0 revogue).
} 
eutanásia contra um pedido do paciente [no sentido de que não o matem ou de que não o deixem morrer].

\section{Os arts. 2. e 8.ำ da Convenção Europeia dos Direitos do Homem}

A Convenção Europeia dos Direitos do Homem contém duas disposições (potencialmente) relevantes para a resolução dos problemas relacionados com o fim da vida - a primeira consta do art. 2. ${ }^{\circ}$, em que se consagra o direito à vida, e a segunda do

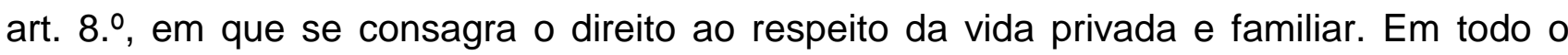
caso, como acontece com todas as grandes convenções, com todas as grandes constituições ou com todos os grandes códigos, a Convenção Europeia dos Direitos do Homem não nos dá respostas.

Em lugar de respostas, a Convenção Europeia dos Direitos do Homem dá-nos o quadro dentro do qual deve procurar-se as respostas para particulares problemas práticos (15) Em lugar de respostas aos problemas da eutanásia, activa e passiva, voluntária e involuntária, os arts. $2 .^{\circ}$ e $8 .^{\circ}$ da Convenção Europeia dos Direitos do Homem dão-nos o quadro dentro do qual deve procurar-se argumentos relevantes para a resposta aos problemas práticos relacionados com o fim da vida.

I. - O art. 2. da Convenção Europeia dos Direitos do Homem (16) sobre o direito à vida, coloca a cargo dos Estados dois tipos de deveres. Em primeiro lugar, deveres de conteúdo negativo. O art. 2. $\stackrel{\circ}{\mathrm{n}} . \stackrel{\circ}{1}$, da Convenção Europeia dos Direitos do Homem ao afirmar que ninguém pode ser intencionalmente privado da vida ${ }^{4}$, está a dizer que os Estados se encontram adstritos a um dever de não agir - de não causar a morte de nenhuma pessoa, privando-a de um bem ou de um valor tão fundamental como a vida. $\mathrm{O}$ Tribunal Europeu dos Direitos do Homem fala de uma obrigação negativa. Convocando os conceitos de Claus Canaris, poderia falar-se de uma proibição de intervenção (17) — por

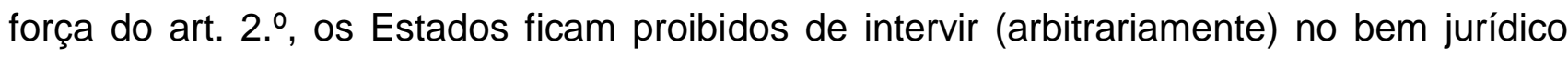
vida. Em segundo lugar, o art. 2. ${ }^{\circ}$ da Convenção Europeia dos Direitos do Homem coloca a cargo dos Estados deveres de conteúdo positivo. O art. 2.ํ, n.ำ 1, ao afirmar, implicitamente, que toda e qualquer pessoa tem direito à vida e, explicitamente, que o

\footnotetext{
${ }^{4} \mathrm{O}$ texto do art. 2. ${ }^{\circ}, \mathrm{n} .^{\circ} 1$, 2. $^{\text {a }}$ parte, continua com as seguintes palavras : “... salvo em execução de sentença capital pronunciada por um tribunal, no caso de o crime ser punido com esta pena pela lei”.
} 
direito de qualquer pessoa à vida é protegido pela lei, está a dizer que os Estados se encontram adstritos a um dever de agir para proteger a vida. O Tribunal Europeu dos Direitos do Homem fala de uma obrigação positiva. Convocando os conceitos de Claus Canaris, poderia falar-se de um imperativo de intervenção, sob a forma de um imperativo de tutela - por força do art. 2.. , os Estados ficam obrigados a intervir, para proteger o bem jurídico vida (para tutelar o bem jurídico vida). O conteúdo do imperativo de intervenção deduzido do art. 2.. carece em todo o caso de algum esclarecimento. O Tribunal Europeu dos Direitos do Homem representa-o com o "dever de tomar todas as medidas necessárias à protecção da vida" função administrativa. O quadro legislativo e, dentro do quadro legislativo, a actividade administrativa de cada Estado deveriam ser apropriados para uma prevenção eficaz dos perigos de lesão dos bens e dos interesses protegidos pelo direito à vida ${ }^{6}$.

II. - Enquanto o bem jurídico protegido pelo art. 2. da Convenção Europeia é ainda susceptível de uma definição mais ou menos precisa, o bem jurídico protegido pelo art. 8.ํ, esse, não o é (18), (19) $\bigcirc$ conceito de vida privada do art. 8. é muito amplo, "manifestamente mais amplo que o de intimidade" (20) - com o termo vida privada, pretende-se designar uma esfera dentro da qual a pessoa pode construir e re-construir livremente a sua personalidade (21) Entre os corolários do direito ao respeito pela vida privada contam-se, designadamente, o direito de cada pessoa conduzir livremente a sua vida pessoal dentro de um "círculo íntimo" ; o direito de cada pessoa desenvolver relações com as demais pessoas ; o direito de cada pessoa desenvolver relações com o mundo, trate-se do mundo da natureza ou do mundo da cultura ; o direito ao respeito da sua integridade física e o direito ao respeito da sua integridade psíquica ; e, sobretudo, o direito ao respeito pela sua liberdade (22) (23) (24).

O acórdão de 29 de Julho de 2002, no caso Pretty contra o Reino Unido, afirma que "a ideia de autonomia pessoal é um importante princípio subjacente à interpretação das garantias do art. 8. ํㅡ da Convenção Europeia dos Direitos do Homem" ${ }^{7}$ e os acórdãos subsequentes - como, p. ex., o acórdão de 30 de Janeiro de 2011, no caso Haas contra a

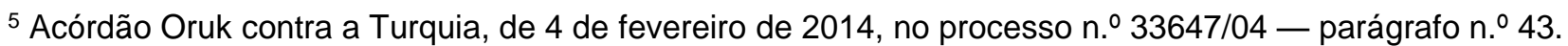

${ }^{6}$ Acórdão Cizek contra a Turquia, de 23 de fevereiro de 2016, no processo n. 0 55354/11 - parágrafos n. ${ }^{\circ} 45$ a n.. 48.

${ }^{7}$ Acordão do Tribunal Europeu dos Direitos do Homem de 29 de julho de 2002 (Pretty contra o Reino Unido) - parágrafo 61.
} 
Suíça ${ }^{8}$, ou o acórdão de 8 de Novembro de 2011, no caso V. C. contra a Eslováquia ${ }^{9}-$ confirmam-no, deduzindo do art. 8.. , designadamente, de um direito ao desenvolvimento pessoal ${ }^{10}$.

O facto de o Tribunal Europeu dos Direitos do Homem definir, em termos tão amplos, o conceito de vida privada faz com que o direito ao respeito da vida privada corresponda, sensivelmente, ao direito geral de personalidade do direito alemão e do direito português - como acontece com o direito geral de personalidade, (re)construído pelo Tribunal Constitucional Federal alemão e pelo Tribunal Constitucional português, o centro ou núcleo do direito ao respeito da vida privada corresponde ao direito ao desenvolvimento da personalidade.

\section{O direito de autodeterminação sobre o processo da morte}

I. - O acórdão do Tribunal Europeu dos Direito do Homem de 29 de julho de 2002, no caso Pretty contra o Reino Unido (25) (26) (27) (28) (29) (30), foi chamado a pronunciarse sobre se o direito à vida, garantido pelo art. 2.. da Convenção Europeia dos Direitos do Homem, deve representar-se como um direito com um duplo aspecto, positivo e negativo.

Em relação ao direito ou à liberdade de associação, consignada no art. 11.. , o Tribunal Europeu dos Direitos do Homem distinguira um aspecto ou dimensão positiva concretizado na liberdade de constituir uma associação ou de aderir a uma associação constituída - e um aspecto ou dimensão negativa - concretizado na liberdade de não aderir a nenhuma associação. Em relação ao direito à vida, deveria porventura fazer-se um raciocínio semelhante, distinguindo um aspecto ou dimensão positiva, o direito a viver, e um aspecto ou dimensão negativa, o direito a não viver ou direito a morrer?

O Tribunal Europeu dos Direitos do Homem concluiu que não, alegando que os dois casos, que o caso do direito de associação e o caso do direito à vida, eram casos

\footnotetext{
${ }^{8}$ Acórdão do Tribunal Europeu dos Direitos do Homem de 30 de janeiro de 2011 (Haas contra a Suíça) — parágrafo 50:

9 Acórdão do Tribunal Europeu dos Direitos do Homem de 8 de Novembro de 2011 (V. C. contra a Eslováquia) - parágrafo 138: "Private life' is a broad term, encompassing, inter alia, aspects of an individual's physical, psychological and social identity such as the right to personal autonomy and personal development, the right to establish and develop relationships with other human beings and the right to respect for both the decisions to have and not to have a child".

10 Acórdão do Tribunal Europeu dos Direitos do Homem de 8 de novembro de 2011 (V. C. contra a Eslováquia) — parágrafo 138
} 


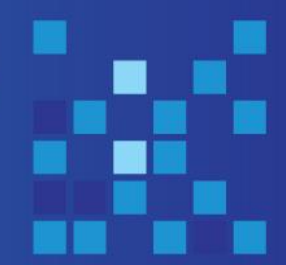

diferentes. $\mathrm{O}$ art. 2.. fala de um direito e $\mathrm{O}$ art. 11.. fala de uma liberdade. $\mathrm{O}$ conceito de direito não implica necessariamente uma escolha, ou uma "medida de escolha"; o conceito de liberdade, sim - implica necessariamente "alguma medida de escolha relativamente ao seu exercício ou não exercício"11. Estando em causa um direito - em concreto, o direito à vida -, "o art. $2 .^{\circ}$ não pode[ria], sem distorção de linguagem, ser interpretado de forma a atribuir a uma pessoa o direito diametramente oposto, ou seja, um direito à não vida ou um direito a morrer "12. O direito de autodeterminação, no sentido de um direito de escolha entre a vida e a morte - de um direito de escolha entre viver e morrer - estaria sempre fora do âmbito de protecção do art. 2.. ${ }^{13}$. Caso devesse admitir-se, com o argumento de que corresponde a um aspecto fundamental da condição humana ${ }^{14}$, o aplicador do direito faria bem em procurá-lo dentro do âmbito de protecção de disposições diferentes do art. 2.. - desiganadamente, dentro do âmbito de protecção do direito ao repeito pela vida privada do art. 8.․

II. - Excluída a possibilidade de deduzir do direito à vida, garantido pelo art. 2.․․ o fundamento do direito de autodeterminação sobre o processo da morte, põe-se a possibilidade de deduzi-lo do art. 8.‥ O acórdão de 29 de Julho de 2002 afirma, timidamente, que o direito de autodeterminação garantido pelo art. 8., $\mathrm{n} .-1$, pela Convenção abrange um "direito de [cada pessoa] tomar decisões sobre o seu corpo" ${ }^{15} \mathrm{e}$ que o direito de cada pessoa tomar decisões sobre o seu corpo abrange o direito de evitar uma morte indigna ${ }^{16}$.

\footnotetext{
11 Acordão do Tribunal Europeu dos Direitos do Homem de 29 de Julho de 2002 (Pretty contra o Reino Unido) - parágrafo 39 : "the Court observes that the notion of a freedom implies some measure of choice as to its exercise".

12 Acordão do Tribunal Europeu dos Direitos do Homem de 29 de Julho de 2002 (Pretty contra o Reino Unido) - parágrafo 39 : "Article 2 cannot, without a distortion of language, be interpreted as conferring the diametrically opposite right, namely a right to die".

13 Acórdão do Tribunal Europeu dos Direitos do Homem de 29 de Julho de 2002 (Pretty contra o Reino Unido) - parágrafos 39 e 40.

14 Acórdão do Tribunal Europeu dos Direitos do Homem de 29 de Julho de 2002 (Pretty contra o Reino Unido) - parágrafo 39 : "Article 2 of the Convention is phrased in different terms. It is unconcerned with issues to do with the quality of living or what a person chooses to do with his or her life. To the extent that these aspects are recognised as so fundamental to the human condition that they require protection from State interference, they may be reflected in the rights guaranteed by other Articles of the Convention, or in other international human rights instruments".

${ }^{15}$ Acórdão do Tribunal Europeu dos Direitos do Homem de 29 de Julho de 2002 (Pretty contra Reino Unido) - parágrafo 59

${ }^{16}$ Acórdão do Tribunal Europeu dos Direitos do Homem de 29 de Abril de 2002 — parágrafo 67.
} 
O Tribunal não está preparado para excluir a possibilidade de que [o facto de a requerente ter sido impedida de exercer o seu direito de escolha, para evitar aquilo que considera ser uma morte indigna] constitua uma ingerência no direito ao respeito pela vida privada, garantido pelo art. $8 . \stackrel{\circ}{\text {, n. }} \stackrel{\circ}{1}$, da Convenção ${ }^{17}$.

O Tribunal Europeu dos Direitos do Homem chama ao caso dois argumentos. Em primeiro lugar, um argumento pré-jurídico (sociológico): O aumento da esperança de vida - causado, pelo menos em parte, pelo progresso da ciência médica - faz com que algumas pessoas fiquem preocupadas com a possibilidade de serem forçadas a "arrastarse" (linger) por estados de degradação física e mental, ou pela velhice, em termos tais que conflituam com os princípios e os valores constitutivos da sua identidade pessoal ${ }^{18}$. Em segundo lugar, o Tribunal completa o argumento pré-jurídico (sociológico) com um

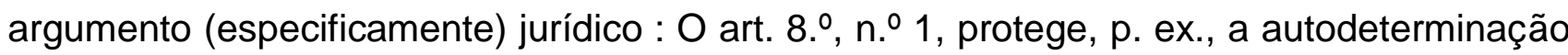
e, em particular, uma autodeterminação conforme aos princípios e aos valores constitutivos da identidade pessoal ; ora, o conteúdo de um direito de autodeterminação [conforme aos princípios e aos valores constitutivos da identidade pessoal] compreenderia, designadamente, o direito à eutanásia activa voluntária - o direito de cada pessoa prevenir a possibilidade de se "arrastar" por estados de degradação física e mental, pronunciando-se sobre o processo da sua morte ${ }^{19}$.

O facto de os termos do acórdão de 29 de julho de 2002 exprimirem, ainda, alguma incerteza foi, entretanto, superado. O acórdão de 30 de janeiro de 2011, no caso Haas contra a Suíça (31), (32) converte todas as incertezas em certezas, ao sustentar que

[o] direito de um indivíduo decidir de que modo e em que momento deve a sua vida terminar, desde que esteja em condições de formar livremente a sua vontade e de agir conforme a sua vontade [livremente formada], é um

\footnotetext{
17 Acórdão do Tribunal Europeu dos Direitos do Homem de 29 de Abril de 2002 - parágrafo 67 : "The Court is not prepared to exclude that this constitutes an interference with her right to respect for private life as guaranteed under Article 8, [paragraph] 1, of the Convention".

${ }_{18}$ Acórdão do Tribunal Europeu dos Direitos do Homem de 29 de julho de 2002 (Pretty contra Reino Unido) - parágrafo 65: "In an era of growing medical sophistication combined with longer life expectancies, many people are concerned that they should not be forced to linger on in old age or in states of advanced physical or mental decrepitude which conflict with strongly held ideas of self and personal identity".

${ }^{19}$ Criticando o acórdão do US Supreme Court no caso Washington v. Glucksberg, por não admitir que o direito ao respeito pela vida privada compreende um direito de autodeterminação sobre o modo e o momento da morte, Erwin Chemerinsky, "Washington v. Glucksberg was Tragically Wrong", in : Michigan Law Review, vol. 106 (2008), págs. 1501-1516.
} 


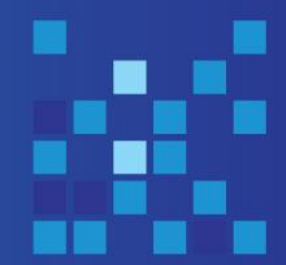

dos aspectos do direito ao respeito da vida privada, protegido pelo art. 8.9 da Convenção 2021.

Como o direito de autodeterminação compreenderia um direito à eutanásia activa, o facto de um Estado proibir a eutanásia activa significaria uma ingerência nos direitos e nas liberdades fundamentais protegidos pela Convenção Europeia - e, em particular, uma ingerência no direito protegido pelo art. 8. da Convenção ${ }^{22}$.

III. - O Tribunal Europeu dos Direitos do Homem sugere que os dois artigos, os arts. 2. e 8.. da Convenção, devem completar-se e esclarecer-se reciprocamente. O imperativo

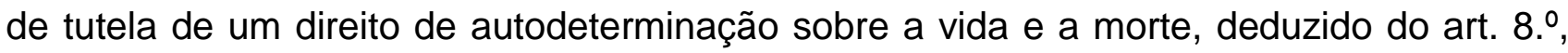
deve completar-se com um imperativo de tutela das pessoas vulneráveis contra os perigos relacionados com a actuação ou o exercício de um direito de autodeterminação sobre a vida e a morte, deduzido do art. 2.‥ Estando em causa pessoas vulneráveis, o imperativo de tutela do direito à vida constitui os Estados num duplo dever de protecção : Em primeiro lugar, os Estados têm o dever de proteger as pessoas vulneráveis contra si próprias e, em segundo lugar, têm o dever de proteger as pessoas vulneráveis contra terceiros. O caso da eutanásia voluntária convoca sobretudo o dever as proteger contra si próprias.

O dever de proteger as pessoas vulneráveis tem como corolário o dever de conformação de um procedimento adequado para que a decisão de cada pessoa seja uma decisão livre e esclarecida. Existindo um procedimento capaz de garantir que a decisão é tomada com plena liberdade e com pleno conhecimento de cauda, o quadro legislativo por que se permitisse a eutanásia poderia corresponder a uma ponderação sustentável dos bens ou valores conflituantes; não existindo um procedimento capaz de o garantir, o quadro legislativo não poderia corresponder-Ihe. - Os Estados teriam, designadamente,

20 Acórdão do Tribunal Europeu dos Direitos do Homem de 30 de janeiro de 2011 (Haas contra a Suíça) parágrafo 51: "the Court considers that an individual's right to decide by what means and at what point his or her life will end, provided he or she is capable of freely reaching a decision on this question and acting in consequence, is one of the aspects of the right to respect for private life within the meaning of Article 8 of the Convention".

21 Confirmando que o acórdão Haas contra a Suíça, de 30 de Janeiro de 2011, corresponde a um desenvolvimento dos critérios enunciados no acórdão Pretty contra o Reino Unido, de 29 de Julho de 2002, vide acórdão do Tribunal Europeu dos Direitos do Homem de 19 de Julho de 2012 (Koch contra Alemanha) - parágrafo 52: "In the case of Haas v. Switzerland, the Court further developed this case-law by acknowledging that an individual's right to decide in which way and at which time his or her life should end, provided that he or she was in a position freely to form her own will and to act accordingly, was one of the aspects of the right to respect for private life within the meaning of Article 8 of the Convention".

22 Acórdão do Tribunal Europeu dos Direitos do Homem de 29 de abril de 2002 - parágrafo 67. 
um dever "de impedir um indívido de pôr fim aos seus dias [p. ex., de se suicidar] se a sua decisão não foi tomada com plena liberdade e com pleno conhecimento de causa"23.

\section{O princípio do tratamento diferenciado dos casos de eutanásia activa e de eutanásia passiva}

I. - O direito ao respeito pela intimidade da vida privada, garantido pelo art. $8 .^{\circ} \mathrm{da}$ Convenção Europeia dos Direitos do Homem, tem como corolário o princípio do consentimento esclarecido ou informado.

O acórdão de 29 de julho de 2002, no caso Pretty contra o Reino Unido, afirma-o:

A imposição de um tratamento sem o consentimento de um paciente que seja, adulto e intelectualmente capaz lesa a integridade física de uma pessoa, de uma tal forma que pode significar uma violação dos direitos protegidos pelo art. 8.. , n. .91 , da Convenção [Europeia dos Direitos do Homem]"24.

O acórdão de 9 de Março de 2004, no caso Glass contra o Reino Unido ${ }^{25}$, como o acórdão de 23 de Março de 2010, no caso M. A. K. e R. K. contra o Reino Unido ${ }^{26}$, ou o acórdão de 8 de Novembro de 2011, no caso V. C. contra a Eslováquia ${ }^{27}$, confirmam-no, desenvolvendo-o em dois pontos : Em primeiro lugar, o conceito de tratamento deve ser interpretado em termos amplos, de forma a abranger toda e qualquer intervenção no domínio da saúde ${ }^{28}$ e, em segundo lugar, o princípio de que um tratamento sem 0

${ }^{23}$ Acórdão do Tribunal Europeu dos Direitos do Homem de 30 de janeiro de 2011 (Haas contra a Suíça) parágrafo 54: "cette dernière disposition [scl. l'article 2 de la Convention] oblige les autorités nationales à empêcher un individu de mettre fin à ses jours si sa décision n'a pas été prise librement et en toute connaissance de cause]".

${ }^{24}$ Cf. acórdão do Tribunal Europeu dos Direitos do Homem de 29 de Julho de 2002 (Pretty contra o Reino Unido) - parágrafo 63 : "the imposition of medical treatment, without the consent of a mentally competent adult patient, would interfere with a person's physical integrity in a manner capable of engaging the rights protected under Article $8 \S 1$ of the Convention".

${ }^{25}$ Acórdão do Tribunal Europeu dos Direitos do Homem de 9 de Março de 2004 (Glass contra o Reino Unido) - esp. parágrafo 70 : "The Court considers that the decision to impose treatment on the first applicant in defiance of the second applicant's objections gave rise to an interference with the first applicant's right to respect for his private life, and in particular his right to physical integrity".

${ }^{26}$ Acórdão do Tribunal Europeu dos Direitos do Homem de 23 de Março de 2010 (M. A. K. e R. K. contra o Reino Unido) - parágrafos 75-80, esp. no parágrafo 77 : "Domestic law and practice clearly requires the consent of either the patient or, if they are incapable of giving consent, a person with appropriate authorization before any medical intervention can take place. Where the patient is a minor, the person with appropriate authorization is the person with parental responsibility. This fully accords with the Council of Europe's Convention on Human Rights and Biomedicine".

${ }^{27}$ Acórdão do Tribunal Europeu dos Direitos do Homem de 8 de novembro de 2011 (V. C. contra Eslováquia) - esp. no parágrafo 141.

${ }^{28}$ Expressão art. 5.ำ da Convenção Europeia dos Direitos do Homem e da Biomedicina. 


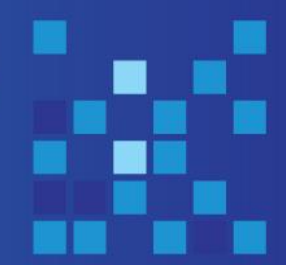

consentimento do paciente é uma violação dos direitos protegidos pelo art. $8 . .9$ da Convenção Europeia dos Direitos do Homem deve ser interpretado em termos amplos, de forma a abranger toda e qualquer intervenção, ainda que seja uma intervenção mínima.

O princípio do consentimento esclarecido ou informado implica logicamente a permissão da eutanásia passiva voluntária: Caso o tratamento seja adequado e necessário para prolongar a vida do paciente, o direito de escolher entre aceitar ou recusar - entre consentir ou não consentir no tratamento proposto é o direito de escolher entre viver ou não viver - entre viver e morrer. O paciente pode, por isso, "actuar ou exercer um direito a não viver (= pode actuar um direito a morrer — right to die) recusando-se a consentir no tratamento que poderia ter o efeito de prolongar a sua vida" 29 .

II. - Em tema de eutanásia passiva por omissão superveniente, ou seja: por interrupção do tratamento, o imperativo de tutela do direito ao respeito da vida privada tem prioridade sobre o direito à vida. O acórdão de 11 de julho de 2006, no caso Burke contra o Reino Unido ${ }^{30}$, propõe-se resolver os casos de interrupção do tratamento por aplicação de dois princípios. O primeiro é o médico não tem o dever de iniciar ou o dever de continuar um tratamento que não seja clinicamente justificado; de que "[n]enhum paciente, seja ou não capaz de consentir, pode exigir ao médico um tratamento que o médico considere clinicamente injustificado"31. O segundo é o de que, na decisão sobre se o tratamento deve ser continuado ou descontinuado, o médico tem o dever de considerar a vontade anteriormente expressa pela pessoa afectada ou, não havendo uma vontade anteriormente expressa, a sua vontade presumíve| ${ }^{32}$. O acórdão de 5 de junho de 2015, no caso Lambert contra a França (32), propõs-se coordenar os dois princípios, dando precedência ao

\footnotetext{
${ }^{29}$ Acórdão do Tribunal Europeu dos Direitos do Homem de 29 de Julho de 2002 (Pretty contra o Reino Unido) - parágrafo 63 : "As recognised in domestic case-law, a person may claim to exercise a choice to die by declining to consent to treatment which might have the effect of prolonging his life".

30 Sobre o acórdão do Tribunal Europeu dos Direitos do Homem de 11 de julho de 2006 (Burke contra o Reino Unido), vide J. K. Mason, "Personal Autonomy and the Right to Treatment: A Note on $R$ (on the application of Burke) v General Medical Council", in: Edinburgh Law Review, vol. 9 (2005), págs. 123-132; John Coggon, "Could the Right to Die with Dignity Represent a New Right to Die in English Law?", in: Medical Law Review, vol. 14 (2006), págs. 219-237.

${ }^{31}$ Acórdão do Tribunal Europeu dos Direitos do Homem de 11 de Julho de 2006 (Burke contra o Reino Unido) : "the Court notes that neither a competent nor an incompetent patient can require that a doctor give treatment which that doctor considers is not clinically justified and thus no difference of treatment arises in that regard".

32 Cf. acórdão do Tribunal Europeu dos Direitos do Homem de 11 de Julho de 2006 (Burke contra o Reino Unido) : "It is apparent that, in the situation apprehended by the applicant in the final stages of his illness, a doctor would be obliged to take account of the applicant's previously expressed wishes and those of the persons close to him ...".
} 
primeiro - dando precedência ao critério da vontade da pessoa afectada. O paciente, como pessoa afectada, ainda que não esteja em condições de exprimir a sua vontade, deverá ser sempre o actor principal e o sujeito principal do processo de decisão ${ }^{33}$.

Coordenando os dois acórdãos, os resultados do raciocínio desenvolvido pelo Tribunal Europeu dos Direitos do Homem podem porventura resumir-se em dois ou em três princípios : Em primeiro lugar, a decisão sobre a continuação do tratamento deve tomar-se atendendo à vontade, real ou presumida, do paciente ; em segundo lugar, só pode descontinuar-se um tratamento contra um pedido do paciente desde que o tratamento seja desadequado e, em terceiro lugar, só pode descontinuar-se um tratamento sem um pedido do paciente desde o tratamento seja desproporcionado (5).

\section{O princípio do tratamento diferenciado dos casos de eutanásia activa directa e de eutanásia activa indirecta}

Considerando agora o caso da eutanásia activa directa (voluntária), poderá perguntar-se: Os Estados terão o dever de reconhecer a cada pessoa um conjunto mínimo de direitos ou um conjunto mínimo de faculdades relacionados com a eutanásia activa, sob pena de violação do direito ao respeito pela vida privada, garantido pelo art. $8 . \stackrel{\circ}{,}$ n..$^{\circ}$, da Convenção Europeia dos Direitos do Homem?

I. - O acórdão de 29 de julho de 2002, no caso Pretty contra o Reino Unido, considerou que a proibição da eutanásia activa directa constituía uma ingerência no direito ao respeito pela vida privada, garantido pelo art. 8.., n. .1 , e que a licitude ou ilicitude da

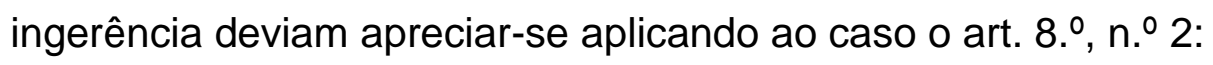

Não pode haver ingerência da autoridade pública no exercício deste direito senão quando esta ingerência estiver prevista na lei e constituir uma providência que, numa sociedade democrática, seja necessária para a segurança nacional, para a segurança pública, para o bem-estar económico do país, a defesa da ordem e a prevenção das infracções penais, a protecção da saúde ou da moral, ou a protecção dos direitos e das liberdades de terceiros".

Encontrando-se preenchido o requisito de que a ingerência estivesse prevista na lei, o problema consistia em determinar se a ingerência era necessária para a protecção da

\footnotetext{
${ }^{33}$ Acórdão do Tribunal Europeu dos Direitos do Homem de 5 de Junho de 2015 (Lambert contra a França) parágrafo 178: "le patient, même hors d'état d'exprimer sa volonté, est celui dont le consentement doit rester au centre du processus décisionnel".
} 
saúde, para a protecção da pessoa contra si própria ou para a protecção da pessoa contra terceiros (=dos direitos e [das] liberdades de terceiros ${ }^{34}$ ).

O acórdão do Tribunal Europeu de 30 de Janeiro de 2011, no caso Haas contra a Suíça, afirma o princípio de que a ingerência no direito de autodeterminada concretizada, p. ex., no condicionamento do acesso a substâncias letais - pode ser necessária para a proteç̧ão da saúde (e, porventura, para a segurança pública) ${ }^{35}$. Independentemente de ser, ou não, necessária para a protecção da saúde, o Tribunal Europeu concorda com o princípio de que a proibição da eutanásia activa directa pode ser necessária para a proteç̧ão das pessoas contra si próprias ou contra terceiros. O perigo de uma perturbação importante da possibilidade fáctica de autodeterminação por causa da ingerência de terceiros é um perigo particularmente sério - por causa, p. ex., das pressões sociais sobre pessoas com uma idade avançada ou, ainda que sem uma idade avançada, com uma doença terminal. Ou bem que o Estado consegue conformar um procedimento adequado para proteger as pessoas na fase final da sua a vida ou bem não consegue fazê-lo (33) - conseguindo conformá-lo poderá e deverá afirmar a licitude ou negar a ilicitude da eutanásia ; não o conseguindo, não poderá fazê-lo (34

II. - O caso apreciado pelo acórdão de 29 de Julho de 2002 confronta-nos com uma questão-limite: a requerente (Diane Pretty) era plenamente capaz e, sendo plenamente capaz, tinha declarado uma vontade constante, livre e esclarecida de morrer ${ }^{36}$. Como a requerente não podia ser considerada uma pessoa vulnerável, a proibição da eutanásia activa directa com o argumento de que a ingerência no direito de autodeterminação era necessária para a protecção das pessoas vulnerávels poderia de alguma forma sustentarse?

Em diferentes palavras, ainda que insistindo em igual pensamento: O problema da proibição da eutanásia põe-se, e põe-se de forma semelhante, para as pessoas vulneráveis e para as pessoas não vulneráveis. O Estado deverá distinguir as pessoas que se encontram em situação de especial fragilidade e as pessoas que não se encontram em situação de especial fragilidade) ?; deverá distinguir as pessoas vulneráveis e as pessoas não vulneráveis, para o efeito de afirmar a ilicitude do suicídio assistido das pessoas

\footnotetext{
${ }^{34}$ Acórdão do Tribunal Europeu dos Direitos do Homem de 29 de abril de 2002 - parágrafo 69.

35 Acórdão do Tribunal Europeu dos Direitos do Homem de 30 de janeiro de 2011 (Haas contra a Suíça) parágrafos 56-61.

${ }^{36}$ Acórdão do Tribunal Europeu dos Direitos do Homem de 29 de abril de 2002 — parágrafo 73.
} 
vulneráveis e a licitude / não ilicitude da eutanásia ou do suicídio assistido das pessoas não vulneráveis ?; deverá distinguir as pessoas vulneráveis e as pessoas não vulneráveis para o efeito de proibir a eutanásia ou o suicído assistido das pessoas vulneráveis e de não proibir (= de permitir) o suicídio assistido das pessoas não vulneráveis ?

O Tribunal Europeu dos Direitos do Homem reconstrói o problema, representando-o nos seguintes termos: a fragilidade abstracta ou típica da categoria ou classe será adequada e/ou suficiente para explicar ou para justificar uma regra aplicável a todos os concretos indivíduos da categoria ou classe designada? $\mathrm{O}$ facto de as pessoas da categoria ou classe designada estarem tipicamente em situação de especial fragilidade explicará / justificará a proibição do suicídio assistido das pessoas que não estão em situação de fragilidade? O acórdão de 29 de Abril de 2002 responde-lhe - e responde-lhe dizendo que sim ${ }^{37}$. Os Estados teriam a prerrogativa de avaliar os riscos da afirmação da licitude ou da negação da ilicitude da eutanásia, para o efeito de determinar se conseguiriam ou não conformar um procedimento adequado para proteger as pessoas em situação de fragilidade ${ }^{38}$. Os acórdãos de 30 de janeiro de 2011 e de 19 de Julho de 2012, esses, não lhe respondem - e, não lhe respondendo, suscitam dúvidas sobre se os princípios enunciados no acórdão de 29 de Abril de 2002 continuam, ou não, em vigor.

III. - Os princípios desenvolvidos para a eutanásia activa directa não devem aplicarse, sem mais, à eutanásia activa indirecta. O acórdão de 9 de Março de 2004, no caso Glass contra o Reino Unido (27) 39 40, confirma explicitamente que a administração de cuidados paliativos sem um consentimento actual, livre e esclarecido de uma pessoa com capacidade para consentir ou do seu representante é em regra ilícita - correspondendo,

\footnotetext{
${ }^{37}$ Acórdão do Tribunal Europeu dos Direitos do Homem de 29 de Abril de 2002 - parágrafo 74 : "The law in issue in this case, section 2 of the 1961 Act, was designed to safeguard life by protecting the weak and vulnerable and especially those who are not in a condition to take informed decisions against acts intended to end life or to assist in ending life. Doubtless the condition of terminally ill individuals will vary. But many will be vulnerable and it is the vulnerability of the class which provides the rationale for the law in question."

38 Acórdão do Tribunal Europeu dos Direitos do Homem de 29 de Abril de 2002 - parágrafo 74 : "It is primarily for States to assess the risk and the likely incidence of abuse if the general prohibition on assisted suicides were relaxed or if exceptions were to be created."

${ }^{39}$ Embora o acórdão de 9 de Março de 2004, no caso Glass contra o Reino Unido, não conste do catálogo, oficial ou quase oficial, de acórdãos sobre o tema do fim da vida [cf. End of Life and the European Convention on Human Rights, in : WWW : < http://www.echr.coe.int/Documents/FS Euthanasia ENG.pdf >], o problema apreciado consistia, exclusiva ou essencialmente, em determinar se a eutanásia activa indirecta era, ou não, admissível

40 Sobre o acórdão do Tribunal Europeu dos Direitos do Homem de 9 de Março de 2004 (Glass contra o Reino Unido), vide PF [= Phil Fennell ?], "The Right of a Treatment Proxy to Challenge a Decision to Administer Diamorphine to a Patient”, in : Medical Law Review, vol. 12 (2004), págs. 317-322.
} 


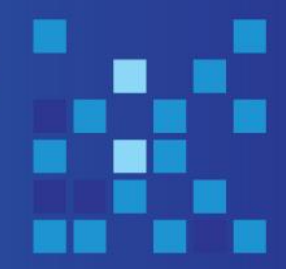

como corresponde a uma violação do direito ao respeito pela vida privada, garantido pelo art. 8. da Convenção Europeia dos Direitos do Homem ${ }^{41}$ - e o acórdão de 19 de Julho de 2012, no caso Koch contra a Alemanha (35) afirma implicitamente que administração de cuidados paliativos com um consentimento actual, livre e esclarecido é em regra lícita.

O parágrafo 25 do acórdão de 19 de Julho de 2012 refere-se à Recomendação do Conselho da Europa n.ำ 1418 (1999), em que se reconhece aos doentes terminais um direito a analgésicos ou a cuidados paliativos e 0 parágrafo 58 , à possibilidade de uma pessoa pedir ao médico que, em simultãneo, administre analgésicos ou cuidados paliativos e descontinue os tratamentos adequados e necessários (p. ex., desligando a máquina de respiração artificial, de que a requerente dependia para que a sua vida continuasse ${ }^{42}$ ).

O Tribunal Europeu dos Direitos do Homem reconhece que o médico tem dois deveres colidentes ou conflituantes - em primeiro lugar, o dever ético e jurídico de agir para conservar a vida ${ }^{43} \mathrm{e}$, em segundo lugar, o dever ético e jurídico de agir para conservar a qualidade de vida, fazendo diminuir o sofrimento do doente ${ }^{44}$. O problema da colisão ou do conflito de deveres deveria resolver-se dando em regra (em toda a regra) precedência ao dever ético e jurídico de agir para conservar a qualidade de vida. Estando em causa "doenças avançadas e progressivas, cujos tratamentos não permitem reverter a sua evolução natural”45, o dever de agir para conservar a vida pesaria ou valeria menos que o dever de agir para conservar a qualidade de vida, diminuindo o sofrimento do paciente ${ }^{46}$.

Se o direito de conformar o processo da sua morte, através de uma eutanásia activa directa, parece ainda ser (só) um direito prima facie, o direito de conformar o processo da

\footnotetext{
${ }^{41}$ Acórdão do Tribunal Europeu dos Direitos do Homem de 9 de Março de 2004 (Glass contra o Reino Unido) - parágrafos 82 e 83.

42 Acórdão do Tribunal Europeu dos Direitos do Homem de 19 de Julho de 2012 (Koch contra Alemanha) parágrafo 58: "B.K. had other possibilities at her disposal to end her life painlessly. In particular, she could have demanded that her doctor switch off the respiratory equipment while being treated with palliative measures. Under the law as applied by the domestic courts at the relevant time [...] her doctor would not have risked criminal responsibility".

${ }^{43}$ Art. 31. do Código Deontológico da Ordem dos Médicos.

${ }^{44}$ Arts, de 16 de Julho, sobre as directivas antecipadas de vontade ; Bases II e III da Lei n.. 52/2012, de 5 de Setembro (Lei de Bases dos Cuidados Paliativos).

45 Expressão do art. 58.ำ n.ำ 2, do Código Deontológico da Ordem dos Médicos.

${ }^{46}$ Douwe Korff, The Right to Life, cit., pág. 16.
} 
sua morte, através de uma eutanásia activa indirecta, parece ser já um direito definitivo $(36)^{47}$.

\section{REFERÊNCIAS}

1. Adragão, PP, A eutanásia: argumentos de um debate. Revista da Faculdade de Direito da Universidade do Porto, 2005

2. Duttge G, Rechtliche Typenbildung: Aktive und passive, direkte und indirekte Sterbehilfe,.in: Dietrich Kettler ;Alfred Simon ;Reiner Anselm ;Volker Lipp ;Gunnar Duttge (coord.), Selbstbestimmung am Lebensende, Universitätsverlag Göttingen 2006,

3. Larenz, K Metodologia da ciência do direito, 3. ${ }^{a}$ ed., Fundação Calouste Gulbenkian, Lisboa, 1997.

4. Picker, E, Menschenwürde und Menschenleben. Zum Auseinander Driften zweier fundamentaler Werte als Ausdruck moderner Tendenzen zur Relativierung des Menschen, In Horst Heinrich Jakobs ; Eduard Picker; Jan Wilhelm; Wolfgang Ernst; Rainer Hütteman. Wolfgang Schön, Festgabe für Werner Flume zum 90. Geburtstag, Springer, Berlin, Heidelberg, 1998

5. Loureiro J Saúde no fim da vida : entre o amor, o saber e o direito. II. - Cuidados. Revista portuguesa de bioética, 2008

6. Young R, Voluntary Euthanasia, in: Edward N. Zalta (coord.), The Stanford Encyclopedia of Philosophy (Fall 2015 Edition). Disponível em:

http://www.plato.stanford.edu/archives/fall2015/entries/euthanasia-voluntary/>.Acesso em 5.jul.2016

7. Raposo, VL . Directivas Antecipadas de Vontade: em busca da lei perdida. Revista do Ministério Público, 2011.

8. Roggendorf ,S, Indirekte Sterbehilfe. Medizinische, rechtliche und ethische Perspektiven, Centaurus Verlag, Freiburg, 2011.

9. Müller-Busch, C Terminale Sedierung - Ausweg im Einzelfall, Mittelweg oder schiefe Ebene?", in: Dietrich Kettler / Alfred Simon / Reiner Anselm / Volker Lipp / Gunnar Duttge (coord.), Selbstbestimmung am Lebensende, Universitätsverlag Göttingen 2006, págs. 124135.

47 O autor esforça-se por conseguir uma "ordenação racional do debate" sobre a eutanásia, contrapondo as áreas de consenso e as áreas de dissenso ("onde se observam divergências assinaláveis"). Entre as áreas de consenso estaria a aceitação da doutrina do duplo efeito: Os actos médicos praticados com a intenção de diminuir o sofrimento, pelo menos, de doentes "com dores insuportáveis", seriam lícitos, ainda que tivessem como consequência ou "efeito colateral" diminuir a duração da vida. 
10. Barroso, LR; Martel, L. A morte como ela é. Dignidade e autonomia individual no fim da vida. Revista da Faculdade de Direito de Uberlândia, 38 (2010): 235-274

11. Díez, JLR Eutanasia y derecho”. In Anuario de filosofia del derecho, v 12 (1995),

12. Müller GA ; Knöbl, J. Der ärztliche Behandlungsabbruch, Änderung der Therapieziele am Lebensende - Rechtssicherheit für den Arzt?". In Hans-Jürgen Ahrens / Christian von Bar ; Gerfried Fischer; Andreas Spickhoff ;Jochen Taupitz (coord.), Medizin und Haftung. Festschrift für Erwin Deutsch zum 80. Geburtstag, Springer, Berlin / Heidelberg, 2009.

13. Lipp, V Rechtliche Grundlagen der Entscheidung über den Einsatz lebenserhaltender Maßnahmen. In Dietrich Kettler ;Alfred Simon ;Reiner Anselm ;Volker Lipp ;Gunnar Duttge (coord.), Selbstbestimmung am Lebensende, Universitätsverlag Göttingen 2006.

14. Singer, P. Practical Ethics, 2. ${ }^{a}$ ed., Cambridge University Press, Cambridge, 1993, págs. 176-180.

15. Sedley, S Foreword to the Fourth Edition In Basil S. Markesinis ; Hannes Unberath, The German Law of Torts. A Comparative Treatise, Hart Publishing, Oxford, Portland (Oregon), 2002.

16. Jayawickrama, $\mathrm{N}$ The Judicial Application of Human Rights Law. National, Regional and International Jurisprudence, Cambridge University Press, Cambridge, 2002: 239-295

17. Canaris, CW. Direitos fundamentais e direito privado. Livraria Almedina, Coimbra, 2003.

18. Kilkelly, U Le droit au respect de la vie privée et familiale, Conseil de l'Europe, Strasbourg, 2003 ;

19. Roagna, I La protection du droit au respect de la vie privée et familiale par la Convention européenne des droits de l'homme, Conseil de l'Europe, Strasbourg, 2012.

20. Rigaux. F La protection de la vie privée et des autres biens de la personnalité, Bruylant / LGDJ, Bruxelles, Paris, 1990

21. La vie privée : une liberté parmi les autres ?, Larcier, Bruxelles, 1992

22. Cohen, J What Privacy is For. Harvard Law Review, 126 (2013):1904-1933.

23. Freeman, M Denying Death its Dominion: Thoughts on the Diane Pretty Case. Medical Law Review, 10 (2002): 245-270.

24. Schutter, O L'aide au suicide devant la Cour européenne des droits de l'homme (À propos de l'arrêt Pretty c. le Royaume Uni du 29 avril 2002). Revue trimestrielle des droits de l'homme, 2003: 71-111. 
25. Biggs, H A Pretty Fine Line: Life, Death, Autonomy and Letting It B. Feminist Legal Studies, 11 (2003): 291-301.

26. Sanz, SC El comienzo y el fin de la vida humana ante el Tribunal Europeo de Derechos Humanos : el aborto y la eutanasia a debate. Cuadernos Europeos de Deusto 31 (2004):157-181;

27. Pridgeon, J. L. Euthanasia Legislation in the European Union: Is a Universal Law Possible?, Hanse Law Review, 2 (2006): 45-60 (56-57).

28. Lewis, P. Medical Treatment of Dementia Patients at the End of Life : Can the Law Accomodate the Personal Identity and Welfare Problems ? European Journal of Health Law, 13 (2006): 219-234 (231-233)

29. Rietiker, D, From Prevention to Facilitation? Suicide in the Jurisprudence of the ECtHR in the Light of the Recent Haas v. Switzerland Judgment. Harvard Human Rights Journal, 25 (2012):85-126;

30. Koubi-Flotte, PO Le régime juridique de la fin de vie dans de droit de la CEDH, B-I; Gregor Puppinck; Claire de La Hougue, The right to assisted suicide in the case law of the European Court of Human Rights

31. Donnaruma, MR, L'affaire Lambert. La jurisprudence française face à la 'fin de vie, Nomos. Le attualità nel diritto, n. 2/2014, Disponível em< http://www.nomosleattualitaneldiritto.it/nomos/maria-rosaria-donnarumma-laffaire-lambert-la-jurisprudencefrancaise-face-a-la-fin-de-vie/ Acesso em 7 jul 2016

32. MacCrorie, B. Os limites da renúncia a direitos fundamentais nas relações entre particulares, Livraria Almedina, Coimbra, 2013

33. Nussbaum, M Human Dignity and Political Entitlements. Human Dignity and Bioethics. Essays Commissioned by the President's Council on Bioethics, Washington, 2008: 351-380 (373).

34. Dute, J ECHR 2013/1 Case of Koch V. Cermany, 19 July 2012, no. 497/09 (Former Fifth Section). European Journal of Health Law, 20 (2013),: 79-82

35. Pereira, AD Direitos dos pacientes e responsabilidade médica, Centro de Direito Biomédico [da Faculdade de Direito da Universidade de Coimbra] / Coimbra Editora, Coimbra, 2015. 